удк 340.132

\title{
A.А. Петров
}

\section{МОЖЕТ ЛИ КОЛЛИЗИЯ ЮРИДИЧЕСКИХ НОРМ ПОРОЖДАТЬ ПРОБЕЛ В ПРАВЕ?}

\author{
Статья подготовлена в рамках выполнения НИР по гранту Президента РФ для государственной поддержки \\ молодых российских ученых МК-4819.2018.6 («Совпадение коллизий норм права»).
}

\begin{abstract}
Изучается вопрос, можно ли квалифицировать непреодолимую коллизию правовых норм одновременно еще и как юридическую лакуну (так называемые существущие коллизионные пробелы в праве). Для этого изучаются высказанные отечественными и зарубежными правоведами идеи и их аргументация, рассматриваются реальные примеры таких коллизий. Обосновывается вывод о принципиальной несводимости антиномий норм к юридическим лакунам. Таким образом, способы восполнения пробелов неприменимы для таких коллизий норм права.

Ключевые слова: коллизия норм права; преодоление коллизий в праве; пробел в праве; способы восполнения пробелов в праве; коллизионный пробел.
\end{abstract}

Казалось бы, в теории права сложно представить понятия столь разные по смыслу, чем юридические лакуны и коллизии в праве. Однако их объединяет то, что, они, являясь результатом правотворчества [1. С. 36], относятся к юридико-техническим дефектам позитивного права [2]. Дальше начинаются различия: коллизии являются следствием чрезмерной, излишней регламентации определенных сфер общественной жизни а пробелы, напротив, порождены недостаточным числом правил для определенных ситуаций. По справедливому мнению К.Э. Альчуррона и Е.В. Булыгина, в случае коллизии нормативная «система имеет излишние нормы, и для решения проблемы требуется удаление по меньшей мере одной из конфликтующих норм» [3. С. 221]. Напротив, как отмечается авторами «Нормативных систем», пробел в праве предполагает неполноту правовой регламентации: «Понятие нормативного пробела должно быть определено в терминах нормативного определения. Действие p (принадлежащее к определенному классу действий Н) нормативно определено в системе $\mathrm{S}$, если и только если $\mathrm{p}$ разрешено или запрещено в $\mathrm{S}$, то есть норма вида "Рp" или “О-p принадлежит S". Когда одно из действий класса $\mathrm{H}$ не определено в $\mathrm{S}$, имеется пробел и система $\mathrm{S}$ неполна в отношении $\mathrm{H}$. Только когда все действия из класса $\mathrm{H}$ определены, система $\mathrm{S}$ полна в отношении Н. Полнота (пробел) есть, следовательно, относительное понятие: это отношение между системой норм и классом действий, а не (абсолютное) свойство системы, - положение которое часто юристы упускают из виду» [Там же. С. 220].

Между тем, несмотря на качественно различную природу, общие следствия пробелов и коллизий сходны: «...в обоих случаях система терпит крах в ее самой важной функции - функции регулирования поведения» [Там же. С. 221]. Более того, в «пространстве права» есть точка, в которой возникает вопрос о содержательном пересечении указанных ноуменов.

Речь идет о следующих ситуациях: легислатура в одном и том же формальном источнике права закрепляет две (или более) нормы, одинаковые по объему регулирования (адресованные одним и тем же субъектам в идентично моделируемых фактических ситуациях) и действующие на одной территории, но содержательно отличающиеся друг от друга - так, что реализация одной нормы с необходимостью означает нарушение другой.
Конечно, такого рода антиномии норм свидетельствуют о крайне низкой культуре законотворчества. Однако они все же встречаются в позитивном праве.

Так, ознакомившись с формулировкой ч. 6 ст. 103 Уголовно-исполнительного кодекса России от 08.01.1997 № 1-Ф3, следует прийти к выводу о том, что осужденным к отбыванию уголовного наказания в виде лишения свободы запрещается прекращать работу для разрешения трудовых конфликтов, а любой отказ от работы или прекращение работы будет квалифицирован как злостное нарушение установленного порядка отбывания наказания. Вместе с тем в силу ч. 1 ст. 116 того же кодекса лишь отказ от работы или прекращение работы без уважительных причин следует рассматривать как злостное нарушение установленного порядка отбывания наказания. В приведенном примере налицо два различных по содержанию запрета для осужденных: (1) универсальный запрет на отказ от работы или прекращение работы и (2) запрет на отказ от работы или прекращение работы без уважительных причин. Указанные запреты содержатся в одном и том же нормативном акте (уже в его первоначальной редакции), рассчитаны на регламентацию одного и того же общественного отношения; одинаков и их адресат [4. С. 53].

Другой пример непреодолимой коллизии проанализирован В.В. Ершовым [5. С. 11]. В абзаце 3 ст. 72 Трудового кодекса РФ от 30.12.2001 № 197-Ф3 устанавливается, что «не является переводом на другую постоянную работу и не требует согласия работника перемещение его в той же организации... в другое структурное подразделение этой организации в той же местности... если это не влечет за собой изменения трудовой функции и изменения существенных условий трудового договора». Но согласно ст. 57 того же кодекса (в редакции, действовавшей до принятия Федерального закона от 30.06.2006 № 90-Ф3) к числу существенных условий трудового договора, которые не могут быть изменены односторонними действиями лишь работодателя, относилось место работы (с указанием структурного подразделения). Очевидно, что указанные нормы противоречили друг другу до середины 2006 г. в части решения вопроса о наличии у работодателя обязанности согласовывать с работником его перемещение в иное структурное подразделение, если оно было указано в трудовом договоре: пра- 
вило, закрепленное в абз. 3 ст. 72 Трудового кодекса, отрицало наличие такой обязанности, а в ст. 57 Трудового кодекса, наоборот, она закреплялась. Таким образом, Трудовой кодекс России заключал в себе рассогласованные нормы, рассчитанные на упорядочивание одной и той же ситуации, одинаковые по объему регулирования, адресованные одним и тем же субъектам (работодателю и работнику).

Подобного плана коллизии встречаются и в зарубежных правопорядках. Так, Л. Фуллер приводит такой пример: «В деле United States v Cardiff президент компании по производству продовольствия был обвинен в преступном отказе в доступе на фабрику федеральному инспектору, который должен был определить, соответствует ли она федеральному Закону о продовольствии, лекарствах и косметике. Условия, при которых инспектор может посетить фабрику, определяются в разделе 704 этого закона. Одно из этих условий состоит в том, что вначале необходимо получить разрешение владельца. Раздел 331 объявляет преступлением отказ владельца фабрики “разрешить вход или осмотр, признанные законными в разделе 704". Таки образом, получается, что закон гласит, что у инспектора есть право посетить производство, но при этом у владельца есть право не допустить его, отказав в доступе» [6. С. 85].

Как видим, в приведенных примерах налицо признаки коллизии правовых норм: есть несколько правил поведения, порождающих рассогласованность, противоречивость правовой регламентации одной и той же фактической ситуации. Однако критерий преодоления такой коллизии, безусловно, туманен (нормы созданы одним и тем же органом, обладают одинаковой юридической силой, совпадают по объёму, приняты одновременно и действуют на одной территории). То есть указанная коллизия не может быть квалифицирована ни как иерархическая, ни как содержательная, ни как темпоральная, ни как пространственная [7].

Правоведы, конечно же, не обошли подобные ситуации стороной в своих теоретических рассуждениях.

Так, по мнению Е.В. Васьковского, в таких случаях коллидирующие нормы «не могут быть примирены между собою и... нет достаточного основания для того, чтобы отдать преимущество» [8. С. 80] какойлибо из них. Поэтому, продолжал он, «не остается ничего иного, как признать их взаимно уничтожающими друг друга, т.е. не существующими» [Там же].

В доктрине встречается мысль, что лишь такие, непреодолимые, непримиримые антиномии норм следует называть истинными коллизиями в праве, а те антиномии юридических правил, которые могут быть преодолены путем применения коллизионных норм, таковыми не являются. Об этом писал, в частности, Б. Виндшейд, полагавший, что в описываемой ситуации происходят взаимная аннигиляция коллидирующих норм, их изъятие из корпуса позитивного права. Немецкий правовед замечал: «...если противоречие вовсе не мнимое (и притом непримиримое), и если нельзя также доказать, что истинная мысль законодателя выражается в одном из этих правоположений более, чем в другом, то следует сказать, что первое имеет такую же силу, как и последнее; и что следовательно, первое отменяет последнее; а поэтому должно решать как не было ни того, ни другого» [9. С. 55].

При таком подходе ставится знак равенства между коллизиями и пробелами в праве. Ф. Хек, классифицируя пробелы в праве, называл описываемое явление коллизионным пробелом [10. С. 161; цит. по: 11. С. 375]. В этой связи Е.В. Васьковский, критикуя сам термин «коллизионный пробел», все же отмечал, что «под ним скрывается верная мысль, что когда существуют две противоречивые, отменяющие друг друга нормы и когда это противоречие нельзя устранить, следует вести себя так, словно в праве существует пробел» [11. С. 375]. Заместим, что термин «коллизионный пробел» встречается у многих отечественных и зарубежных авторов [1. С. 36, 39-41; 12. С. 54; С. 13. C. $207 ; 14$. C. $25-30 ; 15 ; 16$. C. $12 ; 17$. C. $35 ; 18$. C. 204 ; 19. С. 4-6; 20. С. 371-372].

«Коллизионный пробел» необходимо отличать от пробела в коллизионном регулировании (это понятие используется в науке международного частного права). В последнем случае в силу дефектности коллизионной нормы либо ее отсутствия для какого-либо отношения, осложненного иностранным элементом, отсутствует возможность применения коллизионных норм [21. С. 22-23; 22. С. 37]. Главным методом восполнения пробела в коллизионном регулировании «является применение гибкой коллизионной нормы» [22. С. 38] (принцип наиболее тесной связи) [23. С. 47], т.е. аналогия закона.

Вопрос непримиримого конфликта правовых норм занимал и Г. Кельзена. Вообще, позиция Кельзена о возможности коллизии норм не отличается последовательностью. В своем «Чистом ученим о праве» 1934 г. [24, 25] Кельзен отвергает возможность коллизии норм права (они не рассматривались им как суждения), однако уже в англоязычном переводе этой работы в 1945 г. он меняет свой подход [26; 27. С. 14, 60-64]. И теперь в чистом учении о праве в случае невозможности применения коллизионных норм и принципов для преодоления конфликта юридических правил, «...либо оба [коллидирующих] положения могут пониматься в том смысле, что правоприменительному органу - например, суду - представляется выбрать между ними, либо (если... две нормы лишь частично противоречат друг другу) вторая норма может пониматься как ограничивающая действительность первой... Если же невозможна ни та ни другая интерпретация, то это значит, что законодатель предписывает нечто бессмысленное, перед нами бессмысленный нормоустанавливающий акт; следовательно, здесь отсутствует какойлибо акт, субъективный смысл которого можно истолковать как его объективный смысл, и потому нет никакой объективно действительной нормы, - и это несмотря на то, что акт был осуществлен в соответствии с основной нормой» [28. С. 83] (заметим, что цитируемый перевод был выполнен по изданию «Чистого учения о праве» 1960 г. [29], поэтому он отражает систему взглядов «позднего» классического Кельзена американского периода [30. С. 3]).

3. Зембиньский осуществил попытку классификации коллизионных пробелов, выделив два их вида: 
1) «логические» пробелы, где одна норма разрешает какое-то действие, а другая его запрещает; 2) «праксиологическое несоответствие» норм, когда результаты реализации одной из них препятствуют достижению результатов другой [13. С. 207].

В.В. Лазарев в числе существенных признаков «коллизионного пробела» называл абсолютный характер противоречия двух правил, порождающий невозможность преодоления правовой коллизии на основании применения коллизионных норм и принципов (таких как lex superior, lex specialis, lex posteriori) [14. C. 25-27], отмечая, что объекты коллизии, порождающей пробел, могут содержаться как в одном, так и в нескольких нормативных правовых актах [Там же. С. 26-27].

Последняя мысль В.В. Лазаревым нуждается в небольшом уточнении. Непреодолимое противоречие правовых норм, как правило, будет отсутствовать в случаях антиномии норм различных (двух и более) нормативных правовых актов, поскольку в этом случае почти всегда можно воспользоваться правилом преодоления темпоральной коллизии. Даже если два нормативных акта, содержащих абсолютно несовместимые нормы, приняты в один и тот же день, в подавляющем большинстве случае можно установить момент их принятия и в этом случае использовать принцип lex posteriori derogat priori. И лишь когда установить точную хронологию голосования за принятие нормативных актов в рамках одного дня нельзя, можно вести речь о неразрешимой коллизии (подобные примеры автору неизвестны, но гипотетически они возможны).

Описав воззрения правоведов, выделяющих «коллизионный пробел» в качестве самостоятельного вида юридических лакун, следует обратиться к природе коллизий и пробелов в праве. На наш взгляд, характеризовать ситуации непреодолимого противоречия норм права как «нормативную пустоту» нельзя. В основу предлагаемой позиции положено следующее:

Во-первых, антиномии норм позитивного права и юридические лакуны вызваны принципиально разными причинами: первые - нормативной избыточностью, т.е. множеством конфликтующих норм права, вторые - нормативной недостаточностью. В момент преодоления (в отличии от устранения) такой коллизии рассогласованные нормы все еще остаются в корпусе позитивного права как действительные и при отсутствии критерия выбора нормы. Более того, вообще в коллизионных ситуациях не всегда очевиден выбор применимой нормы (вспомним хотя бы вопрос об обратной отсылке в международном частном праве, неопределенность в иерархическом соотношений ряда нормативных актов). Если, к примеру, в сфере совместного ведения (ст. 72 Конституции РФ) друг другу будут противоречить нормы постановления Правительства РФ и закона субъекта РФ, нормативная основа для преодоления такой коллизии будет отсутствовать. Но никто не будет вести речь о том, что тем самым указанные нормы уничтожают друг друга. Проблема выбора применимой нормы все равно остается.

Во-вторых, столкнувшийся с ситуацией множества регуляторов поведения для одной ситуации правоприменитель обращается к арсеналу интеллектуаль- ных операций для преодоления коллизий в праве, а не восполнения пробелов. Так, он может попытаться примирить коллидирующие нормы путем их системного и исторического толкования [6. С. 85-88; 31. C. 423-433] либо отказаться признавать наличие коллизии, ограничив, как писал Кельзен [28. С. 83], сферу действия одной из них, либо, наконец, выбрать одну из двух возможных коллидирующих норм, обосновав ее выбор любыми возможными аргументами либо вообще не мотивируя решение. Е.В. Васьковский применительно к последней альтернативе предлагал «отдать предпочтение той из них, относительно которой с большею вероятностью можно предположить, что именно в ней выражена истинная мысль законодателя» [8. С. 81]. Об этом, по его мнению, могут свидетельствовать «либо то обстоятельство, что одна из норм более согласна с другими действующими нормами, либо то, что она помещена именно в том отделе законодательства, который специально относится к данному виду отношений» [Там же].

Так, в приведенном в начале статьи примере конфликта норм ч. 6 ст. 103 и ч. 1 ст. 116 Уголовноисполнительного кодекса России перспективной стратегией преодоления коллизии видится системное истолкование норм в контексте отраслевых и общеправовых принципов (в пользу правила ч. 1 ст. 116 Уголовно-исполнительного кодекса). А разрешения коллизионной ситуации в приведенном противоречии норм Трудового кодекса можно было пойти путем ограничительного толкования пределов действия правила абз. 3 ст. 72 как ущемляющего законные интересы слабой стороны трудовых правоотношений - работника.

Более того, в литературе даже встречаются попытки сформулировать коллизионную норму для преодоления исследуемых антиномий норм в рамках одного акта. Например, в своем трактате о толковании лорд Элсмир сформулировал экстравагантное предложение, «согласно которому при возникновении несовместимостей в пределах родного акта приоритет должно иметь первое из положений - то есть положение, которое является первым по порядку чтения текста» (цит. по: [6. С. 86]). Иронизируя над таким экзотичным подходом, Л. Фуллер справедливо задается вопросом о хоть каком-то его основании: «Интересно, что лежало в основе столь курьезного взгляда. Может, допущение, что к концу своего труда составители закона становятся более утомленными и менее внимательными?» - вопрошает он [Там же]. Однако нет сомнений в том, что это именно попытка преодолеть коллизию, но не восполнить пробел.

Дело в том, что в ситуации непреодолимой рассогласованности правил техника обращения с нормативным материалом принципиально отличается от случаев восполнения пробелов в праве. «Взаимное уничтожение» коллидирующих норм является не более чем метафорой, а правоприменитель, находящийся в положении буриданова осла, все же ограничен в своем выборе потенциально применимых коллидирующих норм теми вариантами, которые предложил ему законодатель. Д.В. Агашев по этому поводу справедливо замечает, что, разделяя идею о том, что «колли- 
зия способна породить пробел, мы вынуждены будем прийти к выводу о том, что избыток нормативного регулирования (коллизия) одновременно означает его отсутствие или недостаток (пробел)» [32. С. 58]. А такое умозаключение является внутреннее противоречивым.

В-третьих, правоприменитель, столкнувшись с такой ситуацией, не может эффективно воспользоваться средствами восполнения пробелов в праве, такими как, например, фиктивное правоприменение путем аналогии закона либо аналогии права, законодательное повеление правоприменителю действовать как будто бы он законодатель (как предлагает, в частности, ст. 1 Швейцарского гражданского уложения 1907 г.), «скрытное» применение аналогии закона или аналогии права, обращение к естественному праву [1]. Это обусловлено тем, что указанные способы представляют собой лекарство от иной болезни - недостатка правовых норм, а не их избытка.

При восполнении пробелов судья или иное уполномоченное лицо черпает основания для принятия решения о восполнении пробела за пределами совокупности норм позитивного права, на основании которого выносит внезаконное предписание [Там же. С. 70] для разрешения какого-либо дела. В случае же непреодолимой коллизии действующих правовых норм при всем желании найти необходимую «пустоту» в позитивном праве не представляется возможным: есть как минимум две формально не отмененные, действующие нормы, которые претендуют на применение в одной и той же ситуации. Отсутствие же критерия преодоления такой коллизии не меняет ее существо как коллизии, не превращает ее в пробел: «...если общественное отношение уже подвергалось правовому урегулированию, то оно (отношение), очевидно, будет находиться под влиянием каждой из коллидирующих норм» [32. С. 58], а «в результате разрешения одна из некоторого множества коллидирующих норм в любом случае должна быть применена к конкретному общественному отношению» [Там же].

Чтобы проиллюстрировать эту идею, смоделируем абсолютное противоречие внутри одного закона. Представим, что закон об образовании в норме N гласит, что преподавателю категорически запрещается любое опоздание на учебное занятие под угрозой увольнения, а в норме $\mathrm{N}_{1}$ содержится правило, разре- шающее преподавателю опоздание на учебное занятие до 15 минут.

Эти два правила, очевидно, являются одновременно несовместимыми в ситуации опоздания преподавателя на занятие на срок до 15 минут. Означает ли это, что они «уничтожают» друг друга и возникает пробел в праве? Оправданно ли поступит суд, рассматривающий трудовой спор об увольнении такого педагога, если для разрешения спора он сформулирует свое правило, отличающееся от норм $\mathrm{N}$ и $\mathrm{N}_{1}$ (например, преподавателю разрешено опаздывать на 7 минут и 30 секунд (ровно половину срока, предусмотренного нашей нормой $\mathrm{N}_{1}$ ) либо преподавателю разрешается опаздывать ровно на одно учебное занятие)? Вряд ли это будет хоть на чем-либо кроме произвола правоприменителя основанное решение. Ведь если есть две нормы позитивного права, противоречащие друг другу, то отказываться выбрать одну из них и формулировать третью - означает бросать открытый вызов требованию законности, провоцируя и иных субъектов на прямое неподчинение позитивному праву.

Все вышеизложенное свидетельствует о недопустимости смешения пробелов и коллизий в праве. Способы восполнения пробелов в праве не могут использоваться для регуляции поведения в случаях непреодолимого противоречия правовых норм. В указанных обстоятельствах следует либо пытаться примирить конфликтующие нормы, либо применить одну их них по выбору (усмотрению) официального лица [28. С. 83], причем основания указанного выбора (либо одна, либо другая норма) очевидно будут лежать за пределами совокупности норм позитивного права. Поэтому предлагаемое Д.В. Агашевым наименование указанной разновидности коллизий - структурные [32. С. 128-129] - не вполне точно отражает их природу как непреодолимого противоречия, оставляющего выбор нормы, подлежащей применению, по сути, на усмотрение правоприменителю. Наверное, более удачно было бы назвать их дискреционными. Лишь последнее обстоятельство в какой-то мере говорит о наличии чего-то общего у процессов восполнения лакун и преодоления дискреционных коллизий в праве. Однако выход за пределы норм позитивного права для поиска оснований юридического решения не является конституирующим признаком самого пробела в праве, поскольку обращение к экстраюридической аргументации вполне возможно и при отсутствии юридических лакун [33. С. 477-480].

\section{ЛИТЕРАТУРА}

1. Дробышевский С.А., Тихонравов Е.Ю. Способы восполнения пробелов в праве. М., 2014. 176 с.

2. Власенко Н.А. Логико-структурные дефекты системы советского права // Правоведение. 1991. № 3. С. $22-28$.

3. Альчуррон К.Э., Булыгин Е.В. О понятии правового порядка // «Нормативные системы» и другие работы по философии права и логике норм. СПб., 2013. С. 211-222.

4. Крымов А.А., Скиба А.П. Коллизии законодательства России (краткий научный комментарий). М., 2016.186 с.

5. Ершов В.В. Судебное правоприменение: актуальные теоретические и практические вопросы // Российское правосудие. 2006. № 5. С. 412.

6. Фуллер Л. Мораль права. М., 2007. 308 с.

7. Власенко Н.А. Коллизионные нормы в советском праве. Иркутск, 1984. 99 с.

8. Васьковский Е.В. Руководство к толкованию и применению законов. М., 1997. 128 с.

9. Виндшейд Б. Учебник пандектного права. Общая часть. СПб., 1874. Т. 1. 375 с.

10. Heck P. Gesetzesauslegung und Interessenjurisprudenz // Archiv für die civilistische Praxis (AcP) / $1914.112 \mathrm{ff}$

11. Васьковский Е.В. Избранные работы польского периода. М., 2016. 640 с.

12. Вильнянский С.И. Толкование и применение гражданско-правовых норм : метод. матер. ВИЮН. М., 1948. Вып. 2. С. 42-61.

13. Ziembinski Z. Podstawy sporow o "luki w prawe" // Panstwo i prawo. 1966. № 2. S. 205-215. 
14. Лазарев В.В. Пробелы в праве и пути их устранения. М., 1974. 184 с.

15. Raz J. Legal Reasons, Sources and gaps // Raz J. The Authority of law. Oxford, 1979. URL: http://www.oxfordscholarship.com/ view/10.1093/acprof:oso/9780198253457.001.0001/acprof-9780198253457-chapter-4.

16. Галаганов В.П. Правоприменительная деятельность в сфере пенсионного обеспечения : автореф. дис. ... канд. юрид. наук. М., 1988.20 с. 17. Лазарев В.В. О видах пробелов в праве // Правоведение. 1969. № 6. С. 30-37.

18. Уранский Ф.Р. Пробелы в праве и способы их восполнения в правоприменительной деятельности : дис. ... канд. юрид. наук. М., 2005. $192 \mathrm{c.}$

19. Портнов А.В., Москалюк О.В. Співвідношення категорій «колізія норм права» і «прогалина в законодавстві» // Ученые записки Таврического национального университета им. В.И. Вернадского. Сер. Юридические науки. 2012. Т. 25 (64), № 1. С. $3-7$.

20. Булыгин Е.В. Когда право молчит // «Нормативные системы» и другие работы по философии права и логике норм. СПб., 2013. С. 371379.

21. Макаров А.Н. Основные начала международного частного права. М., 1924. 151 с.

22. Толстых В.Л. Международное частное право: коллизионное регулирование. СПб., 2004. 526 с.

23. Гетьман-Павлова И.В. Международное частное право : учеб. для магистров. 4-е изд., перераб. и доп. М., 2013. 959 с.

24. Kelsen H. Reine Rechtslehre. Leipzig ; Wien, 1934.

25. Кельзен Г. Чистое учение о праве: введение в проблематику науки о праве 1-е изд. / пер. с нем. М.В. Антонова // Российский ежегодник теории права. 2011. № 4. С. 430-511.

26. Kelsen H. General Theory of Law and State. Cambrige, Mass., 1945.

27. Антонов М.В. Чистое учение о праве против естественного права? // Ганс Кельзен: чистое учение о праве, справедливость и естественное право. СПб., 2015. С. 7-106.

28. Чистое учение о праве Ганса Кельзена : сб. переводов / пер. с нем. С.В. Лезова ; отв. ред. В.Н. Кудрявцев, Н.Н. Разумович. М., 1988. Вып. 2.212 c.

29. Kelsen H. Reine Rechtslehre. Wien, 1960.

30. Чистое учение о праве Ганса Кельзена : сб. переводов / пер. с нем. С.В. Лезова, отв. ред. В.Н. Кудрявцев, Н.Н. Разумович. М., 1987. Вып. 1. 195 с.

31. Савиньи Ф.К. фон. Система современного римского права / пер. с нем. Г. Жигулина ; под ред. О. Кутателадзе, В. Зубаря. М., 2011. Т. І. $510 \mathrm{c}$.

32. Агашев Д.В. Коллизионные проблемы в праве социального обеспечения. Томск, 2005. 272 с.

33. Pound R. Hierarchy of Sources and Forms in Different Systems of Law // Tulane law review. Vol. VII, № 4. P. $467-477$.

Статья представлена научной редакцией «Право» 26 марта 2018 г.

\section{COULD A CONFLICT OF LEGAL NORMS CREATE NORMATIVE GAPS?}

Vestnik Tomskogo gosudarstvennogo universiteta - Tomsk State University Journal, 2018, 432, 218 -223. DOI: $10.17223 / 15617793 / 432 / 29$

Aleksandr A. Petrov, Siberian Federal University (Krasnoyarsk, Russian Federation). E-mail: sfu-pravo@yandex.ru Keywords: conflict of laws; conflict of norms; overlap of conflicts of laws; resolving of conflict of laws; gap in law; collision gap.

The current paper presents some ideas that can be used for a more clear distinction between conflict of norms and normative gaps in law. It is universally recognized that gaps in law and conflict of norms are opposing forms of legal indeterminacy. Fundamental reasons of legal gaps and conflict of norms in the law are different: incompleteness of the normative system in the first case and redundancy of inconsistent norms in the second case. However, the unique protentional point of contact between gaps in law and conflict of norms could be uncovered. Let us imagine a single legal act that includes a set of two incomplete rules for regulation of case $a$ : let us assume that one of them (Norm 1) forbids activity $A$ for persons $p$ in case $a$, and the other rule (Norm 2) permits activity $A$ for persons $p$ in the same case $a$. Obviously, it is conflict of norms contradicting one another. Moreover, we could not use any wellestablished general principle (lex superior, lex specialis, lex posteriori criteria) to resolve such conflict of norms. If it is impossible to harmonize the content of Norm 1 and Norm 2, for instance, via restrictive interpretation of one of them in the context of the content of the other one, there are no universal objective ways to resolve this conflict of norms. Is it correct to describe the illustrated situation as a gap in law because of the "mutual assured annihilation" of any legal norm in case of total (absolute) contradiction? Is it the right way to fill this gap via argument by analogy or via any another way of filling gaps in law? The author strongly disagrees with this point and argues the opposite statement: any conflict of norms could not be a reason for the emergence of a gap in law because of the different nature and origin of legal conflicts and legal gaps as opposite forms of legal indeterminacy. The author believes that normative redundancy does not create incompleteness of regulation, and any enforcer has to resolve the total contradiction on norms via choosing of one of them but not via filling the gaps. The argumentation of the present idea is threefold. First, the author analyzes the current theoretical approaches in legal doctrine and weighs their benefits and disadvantages. Second, the author demonstrates three real cases of the inherent inconsistency between legal norms inside one act and illustrates possible ways of resolving them. The author also simulates a total (absolute) contradiction between two general norms and argues the impossibility of application of techniques and methodologies of legal analogy for resolving such conflict of legal norms. Third, the author analyzes the nature and the origin of normative gaps and conflicts of legal norms to show that the gap between them is unbridgeably wide.

\section{REFERENCES}

1. Drobyshevskiy, S.A. \& Tikhonravov, E.Yu. (2014) Sposoby vospolneniya probelov v prave [Ways to fill in the gaps in the law]. Moscow: Norma.

2. Vlasenko, N.A. (1991) Logiko-strukturnye defekty sistemy sovetskogo prava [Logical andstructural defects of the system of Soviet law]. Pravovedenie. 3. pp. 22-28.

3. Al'churron, K.E. \& Bulygin, E.V. (2013) O ponyatii pravovogo poryadka [On the notion of the legal order]. In: "Normativnye sistemy" $i$ drugie raboty po filosofii prava i logike norm ["Normative systems" and other works on the philosophy of law and the logic of norms]. St. Petersburg: St. Petersburg State University.

4. Krymov, A.A. \& Skiba, A.P. (2016) Kollizii zakonodatel'stva Rossii (kratkiy nauchnyy kommentariy) [Conflicts of Russian legislation (short scientific commentary)]. Ryazan: Akademiya FSIN Rossii.

5. Ershov, V.V. (2006) Sudebnoe pravoprimenenie: aktual'nye teoreticheskie i prakticheskie voprosy [Judicial law enforcement: current theoretical and practical issues]. Rossiyskoe pravosudie. 5. pp. 4-12.

6. Fuller, L. (2007) Moral' prava [Moral of law]. Translated from English. Moscow: IRISEN.

7. Vlasenko, N.A. (1984) Kollizionnye normy v sovetskom prave [Conflicting norms in Soviet law]. Irkutsk: Irkutsk State University. 
8. Vas'kovskiy, E.V. (1997) Rukovodstvo $k$ tolkovaniyu i primeneniyu zakonov [A guide to the interpretation and application of laws]. Moscow: Yuridicheskoe byuro "GORODETs".

9. Vindsheyd, B. (1874) Uchebnik pandektnogo prava. Obshchaya chast' [Textbook of law of pandects. The general part]. Vol. 1. St. Petersburg: Gieroglifov i Nikiforov.

10. Archiv für die civilistische Praxis (AcP) / 112 ff. Heck, P. (1914) Gesetzesauslegung und Interessenjurisprudenz [Law Interpretation and Interest Jurisprudence].

11. Vas'kovskiy, E.V. (2016) Izbrannye raboty pol'skogo perioda [Selected works of the Polish period]. Moscow: Statut.

12. Vil'nyanskiy, S.I. (1948) Tolkovanie i primenenie grazhdansko-pravovykh norm: metod. mater. [Interpretation and application of civil law norms: methodological materials]. Is. 2. Moscow: VIYuN. pp. 42-61.

13. Ziembinski, Z. (1966) Podstawy sporow o "luki w prawe" [Basics of disputes about "gaps in law"]. Panstwo i prawo. 2. pp. $205-215$.

14. Lazarev, V.V. (1974) Probely v prave i puti ikh ustraneniya [Gaps in the law and ways to eliminate them]. Moscow: Yuridicheskaya literatura.

15. Raz, J. (1979) The Authority of law. [Online] Available from: http://www.oxfordscholarship.com/view/10.1093/acprof:oso/ 9780198253457.001.0001/acprof-9780198253457-chapter-4.

16. Galaganov, V.P. (1988) Pravoprimenitel'naya deyatel'nost'v sfere pensionnogo obespecheniya [Law enforcement activity in provision of pensions]. Absract of Law Cand. Diss. Moscow.

17. Lazarev, V.V. (1969) O vidakh probelov v prave [On the types of gaps in law]. Pravovedenie. 6. pp. 30-37.

18. Uranskiy, F.R. (2005) Probely v prave i sposoby ikh vospolneniya v pravoprimenitel'noy deyatel'nosti [Gaps in the law and ways of replenishing them in law enforcement]. Law Cand. Diss. Moscow.

19. Portnov, A.V. \& Moskalyuk, O.V. (2012) Spivvidnoshennya kategoriy "koliziya norm prava" i "progalina v zakonodavstvi" [The ratio of the categories "conflict of law" and "gap in the law"]. Uchenye zapiski Tavricheskogo natsional'nogo universiteta im. V.I. Vernadskogo. Seriya "Yuridicheskie nauki". 25(64):1. pp. 3-7.

20. Bulygin, E.V. (2013) Kogda pravo molchit [When law is silent]. In: Lisanyuk, E.N. (ed.) "Normativnye sistemy”" $i$ drugie raboty po filosofii prava i logike norm ["Normative systems" and other works on the philosophy of law and the logic of norms]. St. Petersburg: St. Petersburg State University.

21. Makarov, A.N. (1924) Osnovnye nachala mezhdunarodnogo chastnogo prava [The basic principles of private international law]. Moscow: Yuridicheskoe izdatel'stvo Narkomyusta RSFSR.

22. Tolstykh, V.L. (2004) Mezhdunarodnoe chastnoe pravo: kollizionnoe regulirovanie [Private international law: conflict regulation]. St. Petersburg: Yuridicheskiy tsentr-Press.

23. Get'man-Pavlova, I.V. (2013) Mezhdunarodnoe chastnoe pravo [International Private Law]. 4th ed. Moscow: Izdatel'stvo Yurayt.

24. Kelsen, H. (1934) Reine Rechtslehre [Pure Theory of Law]. Leipzig; Wien: Deuticke.

25. Kelsen, G. (2011) Chistoe uchenie o prave: vvedenie v problematiku nauki o prave [Pure Theory of Law: an introduction to the problem of the science of law]. 1 st ed. Translated from German by M.V. Antonov. Rossiyskiy ezhegodnik teorii prava. 4. pp. 430-511.

26. Kelsen, H. (1945) General Theory of Law and State. Cambrige, Mass.: Cambridge University Press.

27. Antonov, M.V. (2015) Chistoe uchenie o prave protiv estestvennogo prava? [Pure theory of law against natural law?]. In: Kelsen, H. Chistoe uchenie o prave, spravedlivost' $i$ estestvennoe pravo [Pure theory of law, justice and natural law]. 2nd ed. Translated from German by M.V. Antonov, S.V. Lezov. St. Petersburg: Izdatel'skiy dom "Alef-Press".

28. Kudryavtsev, V.N. \& Razumovich, N.N. (eds) (1988) Chistoe uchenie o prave Gansa Kel'zena: sbornik perevodov [Pure theory of law by Hans Kelsen: a collection of translations]. Translated from German by S.V. Lezov. Is. 2. Moscow: INION RAN.

29. Kelsen, H. (1960) Reine Rechtslehre [Pure Theory of Law]. Wien: Deuticke.

30. Kudryavtsev, V.N. \& Razumovich, N.N. (eds) (1987) Chistoe uchenie o prave Gansa Kel'zena: sbornik perevodov [Pure theory of law by Hans Kelsen: a collection of translations]. Translated from German by S.V. Lezov. Is. 1. Moscow: INION RAN.

31. Savigny, F.C. von. (2011) Sistema sovremennogo rimskogo prava [The system of modern Roman law]. Translated from German by G. Zhigulin. Vol. 1. Moscow: Statut.

32. Agashev, D.V. (2005) Kollizionnye problemy v prave sotsial'nogo obespecheniya [Conflict problems in the law of social security]. Tomsk: Izd-vo NTL.

33. Pound, R. (1933) Hierarchy of Sources and Forms in Different Systems of Law. Tulane Law Review. VII(4). pp. $467-477$.

Received: 26 March 2018 